\title{
INSTITUCIONALIZAÇÃO DE PESSOAS COM PARALISIA CEREBRAL: A DIFÍCIL RELAÇÃO SUJEITO - OUTRO - LINGUAGEM
}

\author{
INSTITUTIONALIZATION OF PEOPLE WITH CEREBRAL PALSY: THE DIFFICULT \\ RELATION SUBJECT - OTHER - LANGUAGE
}

\author{
Maria Francisca Lier-DeVitto \\ Pontifícia Universidade Católica de São Paulo \\ f.lier@uol.com.br \\ Tatiana Lanzarotto Dudas \\ Pontifícia Universidade Católica de São Paulo \\ tatidudas@hotmail.com
}

\begin{abstract}
Na Fonoaudiologia há trabalhos que exploram uma gama de questões relativas ao atendimento de pessoas com Paralisia Cerebral. Praticamente todos são orientados por vertentes organicistas ou sócio-cognitivas. A ausência de oralização, muito frequente em casos graves, talvez tenha um papel nesse caso: pesquisadores e profissionais concluem que se não há fala, a pessoa está fora da linguagem. Supõe-se a pessoa, contudo, capacidades perceptuais e cognitivas, mas não linguísticas. Sob esse raciocínio, a linguagem e seus efeitos sobre o sujeito são ignorados. É exceção neste quadro tradicional uma discussão que teorize de modo consistente sobre linguagem e sobre sujeito (Vasconcellos 1999 e 2010; Dudas 2009). Em outras palavras, são raríssimas as pesquisas que se distanciam do discurso organicista e do sujeito epistêmico. O presente artigo toma a direção da exceção mencionada para refletir sobre a institucionalização de pessoas com Paralisa Cerebral e sobre efeitos subjetivos e clínicos.
\end{abstract}

Palavras-chave: institucionalização, Paralisia Cerebral, Linguagem.

Keywords: institutionalization, Cerebral Palsy, Language.

In the field of speech-language pathology there're researches that explore a range of issues related to looking after people with Cerebral Palsy. They're oriented by social-cognitive aspects. The absence of speech, very common in severe cases of the disease, may have a role in this case: researchers and practitioners conclude that if there's no talk, the person is out of language. It's assumed the person, however, perceptual and cognitive capacities, but not languages. Under such kind of reasoning, language and its effects on the subject are ignored. This traditional framework exception is a discussion that another theory is consistently about language and about subject (Vasconcellos 1999 and 2010; Dudas 2009). Summarizing, are very rare the researches that distance themselves from the speech and organization epistemic subject. This article takes the direction of the exception mentioned to reflect on the institutionalization of people with Cerebral Paralyses and subjective and clinical effects.

(Recibido: 31/1/15; Aceptado: 9/7/15) 


\section{Introdução}

Abordo, neste trabalho, questões que têm me inquietado ao longo de minha prática em instituições de longa permanência para pessoas com Paralisa Cerebral ${ }^{1}$. Desde a graduação em Fonoaudiologia, meu interesse esteve voltado para a atuação clínica com pessoas afetadas pelo quadro médico designado paralisia cerebral (PC), principalmente, aquelas com quadros severos e que, por isso, tornam-se moradores de instituições de longa permanência. Assim, no tempo de minha formação universitária, procurei estágios nesses estabelecimentos e posso afirmar que tanto o modo como as pessoas eram (e são) tratadas, quanto às restrições e dificuldades que essas instituições colocam para um clínico me inquietaram (e inquietam).

Convém assinalar que fonoaudiólogos têm, tradicionalmente, realizado atendimentos guiados por diretrizes do discurso organicista, confiantes que são, em sua grande maioria, nas concepções e direções ditadas pela Medicina: faz-se reabilitação motora, trabalha-se a articulação, procura-se melhorar o padrão alimentar e assim por diante. Resumidamente: a Fonoaudiologia tem mantido o olhar voltado para problemas no organismo. Entende-se que as instituições que abriguem pessoas com PC - casos graves de comprometimento motor, na maioria das vezes, acrescidos por deformidades e/ou outros prejuízos associado (alterações de comportamento, quadros psiquiátricos, déficits intelectuais, visuais, auditivos) - assumam um perfil hospitalar.

Colocar em perspectiva a natureza dessas instituições de longa permanência é importante neste trabalho. Elas são, sem dúvida, calcadas na primazia da doença em detrimento do doente (Foucault [1980] 2006). De fato, ali, a face da doença acaba recobrindo as manifestações do sujeito, de forma avassaladora. Na literatura fonoaudiológica é escassa a discussão sobre essa questão e sobre sua estreita articulação com a linguagem, quando o atendimento é a pessoas com Paralisia Cerebral, que estão institucionalizadas - principalmente se elas nada ou pouco verbalizam. Todos (ou praticamente todos) os profissionais são via de regra, orientados por vertentes organicistas ou sócio-cognitivistas. A falta da "oralização" deve participar da carência de estudos sobre linguagem e sobre a relação sujeito-linguagem: pesquisadores e profissionais parecem concluir que se não há fala, a pessoa está fora da linguagem, mesmo supondo a ela capacidades perceptuais e cognitivas. Nesse tipo de raciocínio, a linguagem e seus efeitos sobre o sujeito são sistematicamente ignorados (assim como sua participação - a da linguagem - na dita construção cognitiva). São praticamente inexistentes autores, como Vasconcellos (1999, 2006, 2010) e Dudas (2009), que tomam direção oposta e encaminham uma teorização sobre linguagem que reflita sobre a clínica e os atendimentos em instituições. Em outras palavras, são raríssimas as pesquisas que se distanciam do discurso organicista e do sujeito epistêmico.

A perspectiva teórica, aqui assumida ${ }^{2}$, dá reconhecimento à "ordem própria da língua" (Saussure 1916: 21). Trata-se de la langue que opera sobre a materialidade linguística. Não se trata, portanto, de descrever uma língua a partir de uma gramática particular, mas de explicar a mobilidade significante que, em casos de patologia resiste às descrições categoriais. Os eixos paradigmático e associativo, depois ressignificados por Jakobson (1960), como processos metafórico e metonímico, iluminam a ideia de funcionamento que caracteriza la langue como "um sistema de relações entre unidades concretas" (Saussure [1916] 1989).

\footnotetext{
${ }^{1}$ Muitas questões, além das que ora discuto fizeram parte também de minha dissertação de Mestrado em 2009 no LAEL PUCSP, orientado pela profa. Dra. Maria Francisca Lier-DeVitto.

2 Trata-se daquela que desenvolvida no Grupo de Pesquisa do CNPq: “Aquisição, Patologias e Clínica de Linguagem”, do LAEL-PUCSP, coordenado pelas professoras Dra. Maria Francisca Lier-DeVitto e Dra. Lucia Arantes.
} 
Sustentou esta posição o estruturalismo europeu, especialmente Jakobson, Benveniste (1966) e, mais recentemente, autores como J-C Milner (1987, 2002) e De Lemos (1992, 2002). Por razões teóricas, de compatibilidade lógica entre linguagem e sujeito, outra concepção de sujeito foi demandada, já que o epistêmico foi banido da esfera da Linguística saussuriana (e chomskyana) ${ }^{3}$. O passo dado caminhou na direção do sujeito do inconsciente, introduzido por Freud e formulado por Lacan $^{4}$, daí a aproximação à área da Psicanálise ${ }^{5}$. Nesse enquadre, a linguagem não é admitida como objeto de conhecimento, que possa ser apreensível por aparato perceptual e que possa ser internalizado como conhecimento. A linguagem é logicamente anterior ao sujeito e perdura após sua morte, i.e., ela tem autonomia relativa em relação ao falante. Nesse sentido é que se lê, na Psicanálise, que o sujeito é “capturado" por ela (Lacan [1960]1998). É a noção de língua (la langue) que pesa aí: um funcionamento autônomo, regido por leis de referência interna e que determina os movimentos da fala - movimentos sempre singulares, já que essa materialidade não é neutra, mas impregnada pelos efeitos da vida do falante. Daí ser central a discussão sobre a relação sujeitolinguagem.

Frente à assistematicidade cambiante de falas de crianças, de falas que resistem à descrição categorial (De Lemos 1982), recusa a idéia de que a linguagem seja, para a criança, "objeto de conhecimento", assim como sustenta a insuficiência de suas capacidades percepto-cognitivas. Nesse ponto, aproxima-se do "problema lógico da aquisição", postulado por Chomsky (1965), embora tome direção teórica diversa para enfrentar este problema. De Lemos (2006) diz que o dito desenvolvimento linguístico tem sido definido, pela área da Aquisição de Linguagem ao longo dos anos, como um processo de aprendizagem ou de construção de conhecimento - em ambos os casos, diz ela, mantém-se a centralidade da linguagem-objeto e do sujeito-epistêmico. Os dados de falas de crianças e de falas sintomáticas (Lier-DeVitto 1998, 2001, 2006 et al) dão razões para sustentar que a linguagem tem face insubordinada (que autoriza a poesia, que se manifesta em seu estado nascente e se expõe nas falas sintomáticas). Essas falas instáveis, heterogêneas resistem à regularização por categorias - pode-se, porém, apreender sua mobilidade extravagante.

A linguagem "captura" o ser e faz dele corpo falante - nesse passe, afirma a Psicanálise, constitui-se o corpo pulsional - corpo falado/significado e significante: parlêtre (Lacan 1960), que se distingue plenamente do être-vivant (Canguilhem, [1966] 2007), do corpo que interessa à medicina. Em Psicanálise, sujeito é "sujeito do desejo (...) um efeito da imersão na linguagem" (Chemama 1995: 208) ${ }^{6}$. Isso significa que ele não é nem o sujeito da compreensão (epistêmico), nem o biológico. $\mathrm{O}$ desejo se manifesta, precisamente, como manifestação do inconsciente, quer dizer, nas deformações do sonho, nos equívocos, nos lapsos, nos atos falhos - verdades que surpreendem o sujeito; verdades que vêm à tona na vida quotidiana, sem dúvida; que ganham dimensão surpreendente na aquisição e trágica nas patologias da linguagem (em que o falante fica refém de uma condição a respeito da qual nada pode fazer para mudar).

\footnotetext{
${ }^{3}$ Ver, sobre isso, Lemos (2002).

${ }^{4}$ Sobre a noção de sujeito sugiro ao leitor a leitura do livro "O sujeito na psicanálise de Freud a Lacan - da questão do sujeito ao sujeito em questão”, de Antonio Godino Cabas (2009), já que a questão é bastante complexa e nesse trabalho pretendo focar a discussão na questão da institucionalização.

${ }^{5}$ A aproximação da clínica à área da Psicanálise e da Linguística pode ser melhor visualizada nos trabalhos do Grupo de Pesquisa do CNPq: "Aquisição, Patologias e Clínica de Linguagem", do LAEL-PUCSP, coordenado pelas professoras Dra. Maria Francisca Lier-DeVitto e Dra. Lucia Arantes.

${ }^{6}$ Desejo não é necessidade (esfera do biológico). Por isso não busca satisfação. Desejo se inscreve na ordem de pedido de reconhecimento do outro - de demanda de amor. Disso resulta a relação entre desejo e demanda. Nesse sentido, também, desejo enquanto demanda é pedido que espera resposta - penetramos assim no fato de que desejo e demanda são efeitos de linguagem. Bom lembrar que o sujeito é nela nomeado, ganha nome, e passa a ser, assim, nela representado.
} 
Não se deve, porém, supor que só há sujeito se há fala oralizada. Mesmo impedido de falar, como corpo da cria humana é corpolinguagem - corpo pulsional (desejante, demandante).

Este ponto é fundamental neste trabalho. Para tornar mais claras as pontuações teóricas, feitas acima, abordo o trabalho de Vasconcellos (1999) com pessoas que apresentam quadro médico de Paralisia Cerebral (PC) e que não falam. A autora mostra que limitações motoras e ausência de fala não barram "olhares" e "gestos" plenos de significação e prontos a significar - eles convocam o outro incessantemente. A pesquisadora afirma que o mínimo de habilidade motora que resta é, portanto, instituído pela linguagem (caso contrário, como imaginar ali um pedido de diálogo?) - é a presença na linguagem que permite que a limitação motora do quadro seja ignorada, ultrapassada. Gestos e olhares endereçados, prossegue ela, dizem de "uma presença significada, significativa e significante na linguagem" (Vasconcellos 2010: 2).

Com base num estudo de caso de uma menina de 7 anos com PC, que utilizava símbolos gráficos de comunicação alternativa e também escrita alfabética, a autora pôde concluir que havia escuta da menina para a fala do outro nos cruzamentos entre símbolos/escrita, oralidade/escrita e escrita/escrita. Havia fala na produção escrita de uma criança que "à revelia do impedimento orgânico (... havia) um corpo marcado pelo simbólico” (idem: 2). Vejamos segmento terapêutico:

Terapeuta no início da sessão - "O que aconteceu no seu fim de semana?"

S. responde mostrando os símbolos de CSA referentes à "mãe", "olho" e após apontou as seguintes letras no alfabeto CAKETA.

Terapeuta - "Ahn? Não entendi. Deixa eu ver o que sua mãe escreveu aqui sobre o fim de semana. Ah! É garganta! A sua mãe olhou a sua garganta!” (Vasconcellos 1999: 86, ênfases minhas).

\section{A criança PC e a instituição de longa permanência}

A criança que chega à instituição de longa permanência recebe, de início, um atestado de portadora de "patologia", que justifica sua presença na instituição e a própria existência da instituição. Um primeiro passo na admissão é o diagnóstico médico de paralisia cerebral em grau severo e profundo. Outro critério é a impossibilidade da criança andar, caracterizando sua dependência e necessidade de ser cuidada pelo outro. O caminho dessas pessoas até a instituição de longa permanência reflete o efeito de estigma do diagnóstico médico para a família, como também (e acima de tudo) a institucionalização representa forte agressão contra o sujeito que é ali "depositado" ao ser retirado do convívio familiar. Assim, o impacto dessa decisão, muitas vezes inevitável, é trágico para a criança PC. A relação com aqueles que dela cuidarão é marcada pelo signo de perda, de afastamento do convívio familiar.

Também, desde a institucionalização, a relação da criança com sua mãe fica bastante afetada por ser atravessada por um profissional que se interpõe ("invade" essa intimidade) e sublinha (mesmo sem querer) o déficit (a sequela da lesão neurológica). Essa dinâmica tende a anular expressões de subjetividade e de singularidade já que o cuidado profissional é norteado pelo discurso organicista que é, por natureza, "objetivo" e instruído pelas características da doença.

Note-se que estamos falando, aqui, da dinâmica de uma tríade (mãe - profissional - bebê) e acentuando que, nela, ganham destaque e prioridade orientações: modo de manter a postura adequada e a forma apropriada para a execução de exercícios motores. Assim, o traçado da constituição de um sujeito é atravessado por contingências ligadas ao real de um corpo prejudicado. Mesmo assim, para que uma criança com problema orgânico tenha possibilidade de advir como sujeito, lembra a psicanalista Coriat (1997), é preciso que se cumpram os passos necessários desse processo, ou seja, aqueles pelos quais todas as crianças passam. 
Muitas vezes ocorre, com bebês com problemas, que a visão do problema obtura a visão da criança. A atenção e a ação da mãe ocupam-se, acima de tudo, do sintoma e, como este afeta apenas uma parte do corpo, o bebê recebe uma estimulação localizada. O que resulta disto para o bebê é que se sublinha a libidinação dessa parte, do músculo ou da função que não funcionam corretamente desde o orgânico (Coriat 1997: 181-182).

Frazão (1996), uma fonoaudióloga, também afirma ser importante considerar o peso que a patologia tem nas relações com o bebê desde o seu nascimento e que, em alguns casos (ou na sua

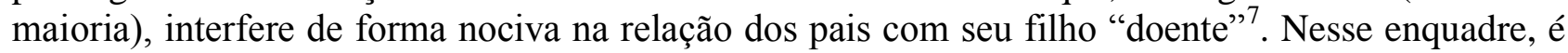
comum, acrescenta ela, os pais atribuírem caráter sintomático a atitudes que são comuns em crianças não lesionadas, ou então, ignorarem manifestações vocais ou gestuais por serem muito distintas das esperadas. Diferente do que ocorre na relação com o bebê não lesionado, Frazão (op. cit.) mostra que, no discurso de alguns pais, marcados pela condição orgânica dos filhos, nota-se forte cristalização de sentidos em torno da patologia. Por isso é que os gestos e vocalizações da criança portadora de Paralisia Cerebral poucas vezes "ganham estatuto linguístico", ou melhor, eles não são interpretados como endereçados, dirigidos ao outro. Algumas vezes, a interpretação pode mesmo "fazer calar" a criança ${ }^{8}$.

René Spitz ([1887] 1979) foi um destacado pesquisador americano que se dedicou à reflexão sobre os efeitos negativos da privação materna e caracterizou como síndrome de hospitalismo a privação afetiva total que crianças sofrem no primeiro ano de vida quando crescem em abrigos, longe da presença da mãe. Em minha prática, tenho assistido a muitas ocorrências de problemas como os mencionados por ele (casos de recusa alimentar, indiferença de estabelecimento de contato visual, balanceios, manipulações de dedos, insônia, falta de apetite, entre outros sinais característicos de isolamento). Muitas vezes, a família abandona definitivamente a criança na instituição. Quando/se retornam, há internos que não os reconhecem mais e não manifestam qualquer tipo de afeto por eles: comportam-se como se os pais fossem estranhos. Todas essas manifestações vão ao encontro do que descreveu Spitz e dão suporte a postulação de que a primeira relação objetal é decisiva na estruturação do sujeito. Pode-se pensar que as instituições, necessárias que são, acabam sendo estabelecimentos pouco propícios à humanização (expressão de SPITZ [1887] 1978).

Spitz procurou iluminar a importância decisiva das "relações objetais" (relações com o outro). Ele destaca que Freud (1905) discutiu sobre as complexas relações entre filho e mãe ("objeto libidinal" $)^{9}$ do ponto de vista do sujeito:

\footnotetext{
A maior parte do primeiro ano de vida é dedicado ao esforço de sobrevivência [...] A cada momento, Freud lembra-nos que a criança, durante este período de sua vida, é indefesa e incapaz de sobreviver por meio de seus próprios recursos. O que falta a uma criança é compensado e fornecido pela mãe. Esta propicia a satisfação de todas as suas necessidades (op. cit.: 23).
}

Spitz distingue síndrome de hospitalismo - privação afetiva total -, e síndrome de depressão anaclítica - privação afetiva parcial. A qualidade de relação que se estabelece com a criança é decisiva para a formação de sua personalidade e mesmo para sua sobrevivência. Experiências traumáticas podem desorganizar sua vida. No caso da depressão anaclítica, a recuperação pode ser rápida se o objeto de amor (o outro) for reinstaurado bem cedo. Já, em se tratando da síndrome de hospitalismo, os danos físicos e psíquicos poderão ser irreversíveis.

\footnotetext{
${ }^{7}$ Termos como esse denotam a posição assumida pelos autores citados e não minha posição, que no decorrer do artigo presumo ficar mais clara.

${ }^{8} \mathrm{O}$ sentido de linguagem citado pela autora diz da comunicação, enquanto que assumo outra posição frente à mesma, já delimitada aqui.

${ }^{9}$ De acordo com o Vocabulário da Psicanálise de Laplanche e Pontalis (2001) "objeto libidinal” é uma expressão introduzida por Freud para distinguir o modo de investimento da libido (energia postulada por ele enquanto substrato das transformações da pulsão sexual quanto ao objeto - deslocamento dos investimentos). Dessa maneira, há a tomada como objeto da própria pessoa ou de um objeto exterior.
} 
O autor explica que cuidados direcionados ao bebê são oportunidades para ações afetivamente significativas. A ausência da mãe equivale à profunda carência emocional, a uma "deterioração" que se manifesta, primeiramente, "por uma interrupção do desenvolvimento psicológico da criança".

Iniciam-se, daí, disfunções psicológicas paralelas a mudanças somáticas, que acarretam uma predisposição crescente a doenças. Quando a privação emocional persiste no segundo ano de vida, Spitz observou a ocorrência de uma taxa extremamente alta de mortalidade. (Spitz 1887-1979: 246). Importa dizer que, segundo a Psicanálise, relações humanas posteriores (a relação amorosa, relação social, profissional e outras) têm sua origem na primeira estrutura de relação a objeto. A relação mãe-filho (pai) estrutura todas as relações futuras de uma pessoa.

Em 1978, Spitz escreveu sobre o "não" e o "sim" do bebê, assumido como solo para o reconhecimento inicial de uma relação de objeto. Crianças separadas de suas mães, por períodos prolongados, têm como primeira reação girar a cabeça ao redor do eixo sagital da coluna vertebral, quando outras pessoas se aproximam (que não seja a enfermeira que as alimenta). Ele interpreta esse movimento como "não", ou seja, como de recusa do outro. O autor notou, ainda, que crianças com síndrome do hospitalismo não apresentam atividades como a sucção do polegar, que são entendidas como auto-eróticas e necessárias. O corpo dessas crianças, embora "cuidado", não foi investido pelo outro ${ }^{10}$.

De fato, em instituições de longa permanência, a noção de doença e de "cuidado" ronda o tempo todo, abafando os espaços para o aparecimento do sujeito. Entendo ser este um caminho perigoso, quando central. Um fonoaudiólogo, se focado apenas à patologia (PC), ficaria concentrado em "exercícios" motores que se interpõem e o distanciam do paciente (como sujeito). É decisivo considerar que, num caso desses, "o paciente não fala, mas escuta - o terapeuta fala, mas não escuta" (Vasconcellos 1999: 4). Uma direção de tratamento que é, de antemão, destinada ao fracasso. Comumente profissionais da Saúde adotam esse ponto de vista. Não se interroga, nem mesmo, o fato de que, muitas vezes, não há coincidência entre sintomas e resultados objetivos. $\mathrm{O}$ ponto é que se toma a direção da objetividade científica, invalidando a opinião do doente em favor da realidade da doença. No caso de pessoas institucionalizadas com Paralisia Cerebral, essa opção é praticamente absoluta: não levam em conta suas queixas - os "cuidados" são decididos pelos cuidadores.

\section{Institucionalização}

Feitas essas considerações iniciais, parto para a reflexão sobre as instituições de longa permanência, sobre a institucionalização de pessoas com Paralisa Cerebral e sobre a difícil relação com o outro, que nelas se efetiva. Minha experiência junto a pacientes institucionalizados mostra que a melhora clínica é sempre sutil e muito lenta. Há, por certo, problemas neurológicos e motores graves, como quadros de disfagia, por exemplo. Porém, outros aspectos são vitais também e eles remetem ao sofrimento de pessoas internadas - principalmente para aquelas que não coordenam músculos e movimentos, que dependem (em todos os sentidos) do outro. Poder considerar que há na PC um corpo falado que fala, no mínimo de movimento que lhe resta, é essencial para essas pessoas.

\footnotetext{
${ }^{10}$ Charles Dickens em Oliver Twist - um menino órfão obrigado a viver em uma casa de correção - foi porta-voz e crítico pioneiro dos prejuízos causados por instituições. No início dos anos 60, Enoch Powell - Ministro da Saúde inglês, em suas visitas a manicômios, testemunhou a forte opressão vivida pelos internos e, em 1961, solicitou o fechamento de todos os manicômios do Sistema de Saúde da Inglaterra, sugerindo sua substituição por alas em hospitais gerais.
} 
Nessas "instituições totais" (expressão de Goffman 2003), o problema de pessoas com PC torna-se mais profundo, porque há normas a serem seguidas: dá-se prioridade aos casos mais graves, ou seja, a doença é privilegiada e não demandas contingenciais dos doentes. Além dessa seleção prévia pela severidade da doença e pela norma, não há número suficiente de profissionais para atender todos os pacientes adequadamente.

Dessa forma, questões de linguagem não emergem como problema e o sujeito é soterrado, reduzido a objeto de cuidados e de manipulação pelo outro. "Vínculos", como se diz nesses estabelecimentos, raramente se estabelecem porque cuidadores e voluntários ocupam-se basicamente de tarefas como: garantir a higiene dos internos e prover alimentação de forma apropriada. Além disso, nem sempre são os mesmos funcionários que cuidam dos mesmos internos: há rodízio. Fui profundamente afetada por este estado de coisas, o que me levou a privilegiar, ou ter em perspectiva, a relação sujeito-linguagem, que implicou uma certa posição de escuta para o outro-terapeuta na realidade institucional com internos com PC.

A minha experiência nesses locais mostrou que, de fato, a rotina de cuidados é bastante rígida. Tem início às seis horas da manhã e, em todos os dias, são os mesmos horários de escovação de dentes, banho, café, almoço, verificação de pressão, entre outros cuidados. Comumente o cardápio é o mesmo (depende de doações de alimentos) e as atividades diárias são, na maioria das vezes, coletivas. Dessa forma, enquanto não há cuidados a serem realizados, os internos permanecem assistindo televisão (escolhido por uma auxiliar de enfermagem ou voluntário), ouvindo músicas ou tomando sol. A rotina é alterada somente em função de datas festivas ou eventos. Quando algum funcionário ou voluntário "concede tempo" ao interno, ele é, quase sempre, advertido porque essa atenção concedida pode "atrasar a rotina". Lembro-me de uma situação em que uma auxiliar de enfermagem, em contrato de experiência, "dava atenção demais a cada criança, sendo que, na instituição, pela rotina atribulada, não havia esse tempo", disse a superiora responsável, que "ficou em dúvida sobre sua contratação", precisamente porque a enfermeira dedicava tempo demais aos internos que atendia. Fato é que, para evitar "vínculo" (como se diz por lá) há alternância dos plantões, compostos por auxiliares de enfermagem. A cada dois meses, o grupo de seis internos é rodiziado entre essas funcionárias para que justamente não haja "apego" "11, entendido como fonte de sofrimento para o interno.

Importante ressaltar também que menos da metade dos internos têm contato com as famílias. A maioria deles foi abandonada na instituição quando ainda criança - as famílias não voltaram para visitar. Há, por certo, algumas famílias presentes que frequentam semanalmente a instituição e ajudam nas tarefas da rotina, mas persiste nos internos o sentimento de abandono. São, além do mais, raríssimos casos em que o juiz concede à família a possibilidade de receber filhos em suas casas para o final de semana porque se considera que elas, as famílias, não têm recursos para realizar os cuidados necessários. Outro fato típico dessa instituição (e de outras) diz respeito aos pertences e objetos pessoais. Internos que usam um sistema alternativo de comunicação ou que até produzem alguma fala, solicitam seus brincos, roupas, livros ou revistas (embora nem sempre sejam atendidos). Aqueles mais prejudicados pela PC, nem mesmo têm pertences: usam roupas e objetos da coletividade. O corte de cabelo é outro exemplo de como a institucionalização pode apagar manifestações de subjetividade e de singularidade: todos passam pelo mesmo cabeleireiro voluntário e têm o mesmo corte: curto; salvo quando alguns internos choram ou gritam como forma de recusa. Não se pode duvidar do fato de que minha atuação na instituição seja diferente da que acontece em consultórios.

\footnotetext{
11 Sobre essa questão, quando algum funcionário dá sinais de forte relação com algum interno, é comum que seja chamada a sua atenção sob a alegação de, um dia, ele pode deixar a instituição e causar sofrimento ao mesmo.
} 
Nas instituições em que atuei, além de atendimentos realizados em uma sala de terapia apropriada e adaptada para este fim, espera-se participação em reuniões escolares, acompanhamento a consultas médicas e passeios. Nessas ocasiões, fui, muitas vezes, colocada na posição de "intérprete" do que os internos "queriam dizer".

Se algum interno se recusava a comer ou chorava ao olhar para a comida, eu era chamada para "dar uma bronca" (o que ocorre quase que diariamente) e, chamada, também, para resolver "malcriações" dos internos que "não colaboram" e que deveriam ser "colocados de castigo" em algum lugar mais afastado (em suas cadeiras de rodas). Entendo que essas convocações apontam para a posição clínica que assumo em instituições: procuro escutar o "corpo que fala", que demanda interpretação. Ou seja, como uma clínica de linguagem, coloco-me ao lado da pessoa com PC.

Importa assinalar que esse "colocar-se ao lado" não deve ser confundido com "maternagem". Não "adoto" certos internos, nem interpreto qualquer vocalização, choro, movimentos. Não os chamo de "filhos", nem de bebês, mas pelo nome. Não "explico" comportamentos (sobre porque o interno "não gosta de acordar cedo", de "comer este ou aquele alimento", que "prefere dormir em outra cama", etc.) - não falo por eles. Devido às limitações expressivas e comunicativas dos internos, procuro estabelecer, nos casos mais graves, um código motor que possa indicar o "sim" e o "não". Pode ser que ele se estabeleça através de movimento ocular, de projeção de braço para "sim", do sorriso ou de uma "cara feia" ou de meneios de cabeça para "sim" e "não". Em alguns casos, Símbolos dos Sistemas gráfico-visuais PCS (Picture Communication Symbols), que fazem parte dos Sistemas Suplementares e Alternativos de Comunicação (SSAC) são utilizados ${ }^{12}$. Tudo depende de cada sujeito (ASHA 1991) ${ }^{13}$.

\section{Instituições de longa permanência}

O termo "institucionalização" tem, de fato, conotação negativa: está fortemente ligado à internação de "doentes mentais" (hospícios e hospitais psiquiátricos), de menores abandonados (abrigos) e de idosos (asilos). Diament e Cypel (1989) apontam para a questão de que há em instituições desde casos de pacientes que têm independência motora e nítida capacidade intelectual, daqueles com maiores deficiências motoras e intelectuais. Há, ainda, casos "irrecuperáveis", que devem ser encaminhados para centros especiais para serem cuidados e para receberem "um tipo de assistência de manutenção" (op. cit.: 807). Fato é que há, sem dúvida, graus de severidade nos casos de pessoas com PC e que, por razões diversas, precisam ser institucionalizadas. Mas, os ditos "casos irrecuperáveis" o são do ponto de vista motor, que exige reconhecer que a PC é, no nível do organismo, um veredicto.

\footnotetext{
${ }^{12}$ Trata-se de "prática clínica, educacional e de pesquisa que tenta compensar, temporária ou permanentemente, os prejuizos e incapacidades de pessoas severamente comprometidas" ${ }^{12}$ (ASHA 1991).

${ }^{13}$ Os Sistemas Suplementares e Alternativos de Comunicação (SSAC) surgiram para facilitar a comunicação. Há uma grande variedade de recursos tecnológicos que envolvem a produção de software, entre outros equipamentos. São vários os Sistemas Gráficos, com diferente simbologia e logística própria, além do uso de fotos, desenhos de alta iconicidade, desenhos abstratos, bem como a ortografia tradicional. Os sistemas gráficos mais conhecidos são: Oakland Schools Symbols, Minspeak, Picsyms, Rebus, Picture Communication Symbols (PCS), Pictogram Ideogram Communication Symbols (PIC) e Blissymbols. O sistema gráfico é o PCS - Picture Communication Symbols -o mais usado no Brasil. O PCS é composto por desenhos com figuras e traços, além da opção de preenchimento colorido, que vêm acompanhados da escrita correspondente acima. Ele mantém a convenção de dividir os símbolos do PCS em seis categorias semânticogramaticais, representadas por cores diferentes: pessoas (amarelo), verbos (verde), sentimentos (azul), objetos (laranja), miscelânia (branco). Além disso, esses símbolos são utilizados em pranchas de comunicação individuais, que consistem em superfícies sobre as quais são dispostos os símbolos que serão indicados pelos seus usuários. Não há uma eleição prévia de símbolos porque as pranchas de comunicação são construídas junto com o paciente de acordo com o texto clínico. O sujeito pode, então, apontá-los ou realizar uma varredura, olhando os símbolos e confirmando o que deseja dizer através de meneios de cabeça ou outro gesto. Ver, sobre isso, Dudas (2009) para maior detalhe e esclarecimentos.
} 
No que concerne ao plano humano, psíquico, contudo, a questão é de outra ordem: a condição subjetiva do paciente depende da qualidade do investimento do outro (de cuidadores e clínicos). Acompanhando Vasconcellos (1999) e Dudas (2009), importa reconhecer, nesse corpo-organismo limitado, a presença de um sujeito desejante.

Mesmo que submetidos a normas institucionais, têm se mostrado viáveis gestos clínicos que abrem espaço para uma relação que dá lugar ao sujeito. Note-se que assinalo uma posição frente ao interno bem diferente da que é caracterizada por Goffman (2003). Mesmo que submetidos a normas institucionais, tem se mostrado viáveis gestos clínicos que abrem espaço para uma relação que dá lugar ao sujeito com PC, como atesto em minha experiência em Instituições.

O termo "institucionalização" tem sido utilizado para descrever tanto o processo, quanto os prejuízos causados pela internação. As instituições foram, originalmente, idealizadas para atingir finalidades benéficas. Contudo, a institucionalização acabou sendo associada ao controle da vida de pessoas subtraídas de todas as possibilidades de interação social - esta, substituída, na verdade, pela rotina de relações alternativas. As características físicas mais importantes dessas instituições totais são lugares como cozinhas, refeitórios e dormitórios - todos coletivos. Não há, como se pode imaginar, espaço para atenção a manifestações subjetivas. Há, além disso, restrições quanto à posse de objetos pessoais.

Goffman (2003), um sociólogo que é um expoente na discussão sobre instituições, define instituição total como:

Local de residência e trabalho, onde grande número de indivíduos, com situação semelhante, separados da sociedade mais ampla por considerável período de tempo, leva uma vida fechada e formalmente administrada. (Goffman 2003: 11) (ênfase minha)

Entende-se porque exemplos de instituições totais são, via de regra, prisões, hospitais de saúde mental e internatos. Também são abarcadas por essa definição, as instituições para pessoas com PC. Segundo Goffman (2003) toda instituição total tenderia ao fechamento, ou seja, seu fechamento caracteriza o caráter total como uma barreira à relação social, com o mundo externo: há evitação ou proibições à saída das pessoas que, na maioria das vezes, é representada pelo aspecto físico das construções: paredes altas, arame farpado, fossos, água.

Goffman classifica as instituições totais em cinco grupos:

(1) instituições criadas para cuidar de pessoas "incapazes" e "inofensivas" (como cegos, velhos, órfãos, indigentes);

(2) locais para cuidar de pessoas consideradas incapazes de cuidar de si mesmas e que são uma ameaça à comunidade, mesmo sem intenção (sanatórios para tuberculosos, hospitais para doentes mentais e leprosários);

(3) instituição organizada para proteger a sociedade contra perigos intencionais (cadeias, penitenciárias, campo de concentração);

(4) instituições estabelecidas para realizar alguma tarefa de trabalho (quartéis, navios, escolas internas, colônias) e, por fim,

(5) estabelecimentos destinados a servir de refúgio do mundo (como abadias, mosteiros, conventos).

Embora não mencionada como exemplo, podemos reconhecer que as instituições destinadas a pessoas com Paralisia Cerebral seriam as do primeiro grupo: aquelas para pessoas "incapazes" $\mathbf{e}$ "inofensivas", em palavras do autor. 
Goffman (2003) diz que aquilo que realmente distingue instituições totais é o fato de cada uma apresentar, em graus diferentes de intensidade, os itens desse conjunto de atributos. Para ele, o aspecto central das instituições totais é a ruptura das barreiras que separam as três esferas da vida da sociedade moderna, que são: “... dormir, brincar e trabalhar em diferentes lugares, com diferentes coparticipantes, sob diferentes autoridades e sem um plano racional geral" (op. cit.: 17). Pode-se imaginar quão perturbada pode ficar a vida familiar daqueles que são internados: "aqueles que comem e dormem no trabalho, com um grupo de companheiros de serviço, dificilmente podem manter uma existência doméstica significativa" (Goffman 2003: 22). De fato, não é incomum observar nas instituições em que atuo confusão de papéis: o funcionário chama o interno de "filho" e se autodenomina ser "mãe" ou "pai", recebendo, inclusive, presentes (feitos durante atividades previstas) de "dia dos pais" ou "dia das mães". Ocorre, porém, que o funcionário tem folga, tem férias e, por vezes, é demitido ou se demite. Pode-se avaliar a artificialidade dessa situação e, ainda, os efeitos que, podem mesmo, ganhar o sentido de segundo abandono por parte desses que se autodenominam "mãe" ou "pai" 14 .

Sobre outros efeitos nefastos da institucionalização de pessoas, o autor indica a aculturação. As pessoas chegam à Instituição com uma cultura aparentemente estabelecida na vida familiar e a longa estada no internato, subverte hábitos, ideologias e costumes antes adquiridos. Assim quando e se uma pessoa internada retorne ao mundo exterior, ela pode sentir-se deslocada e incapaz para "a vida do lado de fora":

\footnotetext{
Para o internado, o sentido completo de 'estar dentro' não existe independentemente do sentido específico que para ele tem 'sair' ou 'ir para fora'. Nesse sentido, as instituições totais realmente não procuram uma vitória cultural. Criam e mantêm um tipo específico de tensão entre o mundo doméstico e o mundo institucional, e usam essa tensão persistente como uma força estratégica no controle de homens. (Goffman 2003: 23) (ênfase minha)
}

Outro efeito da institucionalização é o que o autor chama de processo de mortificação ou de mutilação do eu. As instituições totais devido às importantes e eficientes barreiras que são erigidas entre o internado e o mundo externo ${ }^{15}$. Há, ainda, outras formas de desfiguração pessoal por exposição e violação do corpo através de exames rotineiros, que penetram, sem que haja permissão do interno, a intimidade do indivíduo (segundo Goffman, o território do eu). Além disso, os nomes das pessoas institucionalizadas são substituídos por apelidos e suas correspondências são abertas provas incontestáveis de "invasão de privacidade". O sujeito logo descobre, assinala Goffman, que diante de um ataque ao "eu", ele falha (ou fica impotente). Disso resulta uma posição de subalterno: "a obediência está intimamente relacionada a uma atitude manifesta que não está sujeita ao mesmo grau de pressão para a obediência” (op. cit., p. 40). Entende-se que em muitas situações, nas instituições totais, os internos sejam o lugar de descargas de mau humor, sob efeito de insolência e mesmo sujeitos a castigos. O caráter fechado da instituição promove esse estado de coisas e separa realidade pública e mundo institucional. Correlativo a essa tendência está o fato de toda a instituição total criar um conjunto de práticas institucionalizadas que visam aproximar internados e equipe dirigente e de assistência. Cada uma das atividades diária é realizada na presença ou na companhia imediata de um grupo relativamente grande de pessoas (cuidadores e internos) - todos os internos são tratados da mesma maneira e obrigados a fazer as mesmas atividades em conjunto, em horários rigorosamente estabelecidos e sob um sistema de regras formais explícitas.

\footnotetext{
${ }^{14}$ Entretanto, há funcionários que trabalham na Instituição e que ocupam lugares importantes na vida dos internos, pois convivem com eles diariamente e, muitas vezes, por longos anos. Isso, contudo, não anula a artificialidade da situação e nem os seus efeitos.

${ }^{15}$ É comum haver perda de propriedade - o interno é despojado de seus bens, além de hábitos e privacidade (sofre exposição de informações íntimas sobre sua vida). Os bens que são marcados como pertencentes à instituição. Ora, bens individuais têm relação com $o e u$, lembra Goffman. A perda de propriedade despe o sujeito e promove uma desfiguração pessoal.
} 
Importante, acrescenta Goffman, é que todas essas atividades obrigatórias são realizadas para atender aos objetivos da instituição. Vejamos o que ele diz:

O controle de muitas necessidades humanas pela organização burocrática de grupos completos de pessoas - seja ou não uma necessidade ou meio eficiente de organização social nas circunstâncias - é o fato básico das instituições totais. (Goffman 2003: 18)

Nas instituições totais, observa-se, ainda, a divisão básica entre um grupo grande controlado (grupo dos internados ${ }^{16}$ ) e uma pequena equipe de "supervisão", que responde ao ideal da vigilância. A equipe dirigente trabalha, muitas vezes, oito horas por dia, mas é integrada ao mundo externo. Não é infrequente que a equipe dirigente sinta-se superior e detentora da verdade e do saber. Nesse enquadre, os internados são tratados como inferiores e mais fracos (e assim se sentem!) - o que denota uma nítida configuração do exercício da relação de poder.

As colocações de Goffman (2003) são importantes, a meu ver, na caracterização da natureza das instituições que recebem os pacientes PC. Esse aporte sociológico favorece o entendimento de aspectos que, sem dúvida, subjazem e têm pautado de forma ampla as interações entre profissionais e cuidadores nesses estabelecimentos. Esse autor fala, também, sobre a característica do trabalho nessas instituições - nelas, usualmente, o pagamento em dinheiro nem sempre é adotado. Boa parte das atividades é executada pelos internos e são recompensadas por presentes, por exemplo. Esse sistema desprestigia o trabalho dos internos, desmoraliza aqueles que o executam, como por exemplo, produção de materiais de papelaria para venda, entre outras.

Como se pode ver, mesmo considerando a importância de instituições totais, já que elas são, muitas vezes, a única solução para pessoas deficientes, há efeitos bastante nocivos que não é salutar ignorar, mesmo porque a possibilidade de contorná-los ou evitá-los depende de que eles sejam bem conhecidos. Embora o autor focalize hospitais para doenças psiquiátricas, sua discussão parece-me pertinente porque permite, por extensão, contemplar questões ligadas à "Clínica de Linguagem", que é realizada dentro de instituição total. Ali, como disse, o sujeito isolado do convívio social, não tem também espaço privado - tudo acontece no "coletivo", como vimos, e suas atividades são programadas e altamente normatizadas. Coloco ênfase nesses aspectos para me aproximar de um ponto essencial: “Como exercer, ali, uma clínica?”, Como criar espaço para a intimidade necessária que essa prática demanda?

Guattari ([1930-1992] 2005), psiquiatra, psicanalista e filósofo francês, procurou articular questões levantadas em abordagens sociológicas, como a de Goffman (2003), que focalizam o problema da relação público-privado, com o que chamou de "achatamento da subjetividade". Para ele, o problema do desejo deveria ser inseparável do político e do institucional. Guattari participou de seminários de Jacques Lacan e, por meio dele, aproximou-se da obra freudiana. Trabalhou, com J. Oury, na conceituada clínica psiquiátrica experimental de La Borde. Lá, instituiu uma prática de terapia de grupo e desenvolveu discussão, bastante divulgada e conhecida, a respeito de uma análise institucional. Essa produção de Guattari não esconde, de forma alguma, a influência de suas ideias marxistas.

Em 1995 Guattari e Oury (apud Guattari [1930-1992] 2005), discutiram em La Borde a relação entre enfermeiros e médicos nos hospitais psiquiátricos e procuraram retirar algumas consequências dessa discussão. Eles perguntam, primeiramente, "o que é um médico?" e "o que é um doente?". A resposta à primeira pergunta foi a de que o médico reflete a ideologia de sua classe e assume o papel de defensor das instituições do Estado. Sendo assim, eles tratam de garantir respeito ao regulamento do hospital e se coloca para posição superior frente aos enfermeiros.

\footnotetext{
${ }^{16}$ Vou manter o uso do termo "internados” uma vez que ele é utilizado pelo autor.
} 
Acontece, porém, que o Estado confere poder ao médico, mas não lhe oferece condições adequadas e/ou suficientes para que possa responder à demanda que lhe é dirigida. Isso atesta o fato, dizem os autores, de que também ele, o médico, acaba desprezado pelo Estado e... "detestado pelo enfermeiro". A conclusão a que se chega sobre essa situação nefasta, concluem eles, é que a burocratização das relações e a insuficiência dos serviços prejudicam diretamente o internado. A institucionalização representa, pondera Oury (1995), as instituições garantem tranquilidade da sociedade e, Guattari (1995) completa lembrando que a doença é, em si, alienante. Uma pessoa, ao ser internada, é, antes, alienada/excluída definitivamente da sociedade.

Guattari e Oury trouxeram reflexões importantes sobre o papel do hospital e das relações pessoais (se é que se pode dizer assim) nessas instituições. Apesar de estarem mais voltados para o campo psiquiátrico e para a doença mental, eles sustentam que as questões levantadas e discutidas transcendem hospícios, já que instituições totais (como disse Goffman) reproduzem as mesmas formas de relações sociais. São questões importantes e inusitadas que vão além de análises sociais ou políticas.

Guattari ([1930-1992] 2005) após 15 anos de participação da clínica de La Borde na França e sob efeito de reflexões influenciadas pela Psicanálise. Foi ali, naquele espaço, que ele pode redefinir as bases da psicoterapia institucional. Guattari introduz o conceito da transversalidade no grupo e propõe que ele seja visto como uma "dimensão contrária e complementar às estruturas geradoras de hierarquização piramidal e de modos de transmissão que esterilizam as mensagens" (op. cit.: 116). Essa dimensão corresponderia ao lugar do sujeito do inconsciente no grupo e, por consequência, ao suporte do desejo do grupo - forma de impedir a geração de estruturas de dominação no grupo. Ele visa um grupo pautado pela ideia de alteridade.

Guattari parte da afirmação de que: "por trás de cada caso há um drama humano a decifrar". Para isso, é preciso criar instrumentos de decifração para superar as posições cristalizadas da alienação social, responsáveis pela marginalização de pessoas. Uma seria, sugere o autor, investir na formação dos terapeutas: uma formação dirigida àqueles já implicados e identificados com as dificuldades institucionais - são eles que conhecem os meandros dos internatos e seus efeitos. Guattari aposta numa interação produtiva entre pessoas com tais características. A proposta é caminhar em direção oposta à do movimento psiquiátrico que reflete a segregação entre o mundo dos loucos e do restante da sociedade, movimento desumano e indesejável.

As discussões feitas por Guattari sobre as instituições e as relações de "poder" incluem a problemática da subjetividade. Ela foi incluída pela enfatize colocada na questão da subjetividade, que é definitiva e imperativa para que se possa considerar uma ação clínica em instituições. Não menos importante é a relevância de formar pessoas que já atuam como profissionais e como "cuidadores" nos internatos. Aqueles que ali trabalham devem, entendo com Guattari, poder reconhecer movimentos subjetivos nos internos, i.e., devem poder abandonar ações mecânicas que são dessubjetivantes.

Outro problema nodal, que as deficiências colocam, é que seus efeitos no outro tendem a produzir um retorno que recobre o plano da subjetividade e, nesse movimento, o ser vivo ultrapassa e pode anular o plano humano do ser-falante. Aliás, esse fato é tangível, como já assinalei, no tipo de cuidados que são dispensados aos pacientes PC internados. Sua deficiência é lida como dependência e, "dependência" que denota de um olhar para adultos como se fossem crianças. Daí, a atenção dispensada envolver uma certa infantilização e os cuidados serem do tipo provimento de alimentação e banhos, além de cuidados de enfermaria, como realizar medição sistemática de temperatura e em horários muito bem estabelecidos. 


\section{Considerações finais: sobre o valor de uma posição clínica}

O problema central, que procuro destacar neste artigo, é que nessas instituições, a questão da clínica assume perfil bastante complexo. É improvável que aconteça uma entrevista com familiares, como ocorre em consultórios particulares. O clínico lê prontuários, muitas vezes antigos e escritos por algum funcionário que teve algo a dizer sobre aquela pessoa porque trabalha há mais tempo naquela instituição. Mas, o que ocorre é que ninguém se sente responsável pelos internos, ou seja, não há um responsável por esse ou aquele, mas rodízio de funcionários, pois todos cuidam de todos a partir de um cronograma de tarefas.

A pessoa com PC tem uma história que não pode contar, uma queixa que não pode enunciar e uma demanda que deve e precisa ser decifrada. Queixa e demanda que deveriam e podem ser apreendidas nos movimentos corporais dirigidos ao outro. Assim, menos do que ter como meta a realização de um diagnóstico inicial, o aspecto mais importante é que ocorra mudança de posição do clínico, que ele possa se deslocar para uma posição que "dê voz e vez" (Fonseca 2003) à pessoa com PC. Trata-se de assumir uma posição que não descrimine e não infantilize o paciente ou que o homogeneíze na classe de "deficientes". Trata-se de uma posição clínica devotada à outra ideia de "cuidado". Note-se que sugiro mudança, antes de tudo, no clínico. Assim, sob efeito das críticas às instituições e com base em minha própria experiência como "fonoaudióloga contratada" desses internatos, considero que o passo primeiro e mais essencial a ser dado corresponda ao deslocamento de uma posição cristalizada - posição que foi circunscrita pela ideia de doença, de deficiência e de incapacidade das pessoas com PC.

No caso de instituições, que abrigam pessoas com Paralisia Cerebral, é forte o peso da noção de patologia e de anormalidade no imaginário de profissionais, cuidadores e voluntários. Atribui-se, de imediato, portanto, uma condição de fragilidade (generalizada) à pessoa que chega ali para morar. Não é, igualmente, sem razão, que o modelo de funcionamento desses estabelecimentos seja o hospitalar. Não há dúvida que essas pessoas com PC sejam dependentes para a realização de rotinas de higiene, alimentação e outras, que exijam habilidades motoras obstaculizadas pela incidência dessa afecção neurológica. Essas instituições são necessárias e cumprem até com eficiência as tarefas mencionadas. A questão é que, guiadas por um raciocínio que é típico e próprio do discurso organicista, a dependência motora, que os internos inegavelmente têm do outro, ganha conotações e extensões indevidas. "Dependência" se transmuta em "incapacidade cognitiva", em "impossibilidade de raciocínio".

De fato, sob a esfera de um pensamento organicista, parece que as instituições ficam voltadas para o sofrimento causado por doenças, mas não por outros sofrimentos, motivados por questões humanas: por abandono, desamor ou desconsideração, por exemplo. A restrição ao convívio familiar traz consequências mortíferas, mas considera-se que elas são impossíveis de serem evitadas ou contornadas. Frente a elas assume-se um sentimento de fatalidade. Talvez por isso, "vínculos" devam ser evitados e por isso a instituição comumente assume esse papel, rodiziando funcionários e não permitindo maior contato com este ou aquele interno. Os vínculos são evitados no intuito de barrar sofrimentos e sentimentos que, supõe-se que os internos não tenham e espera-se que nem venham a experimentar. Essa surpreendente lógica é a expressão maior da expansão da "fragilidade motora" no domínio do psíquico.

A cegueira para manifestações do sujeito fica marcada nos cuidados dedicados às pessoas com PC - são cuidados físicos e são indiferentes aos gestos demandantes do sujeito. Procuro, acima de tudo, sustentar uma direção argumentativa que me permita situar e sugerir uma posição para o clínico de linguagem no ambiente institucional. 
Trata-se mesmo, entendo, de uma posição (e não de estabelecimento de procedimentos específicos) - uma posição que se define no reconhecimento de que manifestações corporais da pessoa com PC são significantes, ou seja, são passíveis de serem recolhidas pela interpretação do clínico.

Resumidamente: trata-se de uma posição clínica que admita que, se há ausência de fala oralizada, há um corpo que fala. O clínico de linguagem deve escutar fala mesmo quando ela não é audível - ela está lá no corpo do sujeito. Só assim ele poderá sustentar, mesmo em instituições, uma posição clínica. De fato, não seria apropriado supor que circunstâncias ou estabelecimentos determinem ou definam o que é um clínico. O que o faz um clínico é uma posição singular de escuta para o outro.

\section{Referências Bibliográficas}

American Speech-Language-Hearing Association (ASHA). 1991. Report: augmentative and alternative communication, Vol. 33: 9-12.

Benveniste, Émily. 1966. Problèmes de linguistique gènèrale, Paris, Gallimard.

Canguilhem, Georges. [1966] 2007. O normal e o patológico, Rio de Janeiro, Forense Universitária.

Coriat, Elsa. 1997. Psicanálise e clínica de bebês, Porto Alegre, Artes e Ofícios.

Chemama, Roland. 1995. Dicionário de psicanálise, Larousse, Artes Médicas.

Chomsky, Noam. 1965. Aspects of the theory of syntax, Cambridge, MA: MIT Press.

De Lemos, Claudia Tereza G. 1982. Sobre a aquisição de linguagem e seu dilema (pecado) original, Boletim da ABRALIN, 3: 97-126.

De Lemos, Claudia Tereza G. 1992. Los processos metafóricos y metonímicos como mecanismos de cambio, Substratum, 1: 121-136.

De Lemos, Claudia Tereza G. 2002. Das vicissitudes da fala de criança e de sua investigação, Cadernos de estudos linguísticos, 42: 41-69.

De Lemos, Claudia Tereza G. 2006. Uma crítica (radical) à noção de desenvolvimento na Aquisição de Linguagem, em Maria Francisca Lier-DeVitto \& Lucia Arantes (org.), Aquisição, Patologias e Clínica de Linguagem, São Paulo, EDUC/FAPESP: 21-32.

Diament, Aron e Saul Cypell. 1989. Neurologia infantil, Rio de Janeiro, Atheneu.

Dudas, Tatiana Lanzarotto. 2009. Paralisia cerebral e institucionalização: efeitos subjetivos $e$ clínica de linguagem, Dissertação de Mestrado, LAEL/PUC, São Paulo.

Fonseca, Suzana Carielo da. 2003. O afásico na clínica de linguagem, Tese de doutorado, LAEL/PUC, São Paulo.

Foucault, Michael. [1980] 2006. O nascimento da clínica, Rio de Janeiro, Forense Universitária.

Frazão, Yasmin Sales. 1996. Paralisia Cerebral na clínica fonoaudiológica: primeiras questões sobre linguagem, Dissertação de Mestrado, PUC, São Paulo.

Guattari, Félix. [1930-1992] 2005. Psicanálise e transversalidade: ensaios de análise institucional, São Paulo, Idéias e Letras.

Goffman, Erving. 2003. Manicômios, prisões e conventos, São Paulo, Perspectiva.

Jakobson, Roman. 1960. Closing statement: linguistics and poetics, em Thomas Sebeok, Style in Language, Cambridge, The MIT Press: 350-377

Lacan, Jacques. [1960] 1998. Subversão do sujeito e dialética do desejo, em Escritos, Rio de Janeiro, Jorge Zahar Editor.

Laplanche, Jean e Jean-Bertrand Pontalis. 2001. Vocabulário da Psicanálise, São Paulo, Martins Fontes.

Lier-DeVitto, Maria Francisca. 1998. Os monólogos da criança: delírios da língua, São Paulo, Educ/FAPESP. 
Lier-DeVitto, Maria Francisca. 2001. Sobre o sintoma - déficit de linguagem, efeito da fala no outro, ou ainda...?, Letras de Hoje, Vol. 36, 3: 244-253.

Lier-DeVitto, Maria Francisca. 2006. Patologias da linguagem: sobre as "vicissitudes de falas sintomáticas”, em Maria Francisca Lier-DeVitto \& L. Arantes (org.), Aquisição, Patologias e Clínica de Linguagem, São Paulo, EDUC/FAPESP: 183-200.

Milner, Jean-Claude. 1987. O amor da língua, Porto Alegre, Artes Médicas.

Milner, Jean-Claude. 2002. Périplo estructural, Buenos Aires, Paidós.

Saussure, Ferdinand de. [1916] 1989. Curso de Linguística Geral, São Paulo, Cultrix.

Spitz, René. [1887] 1978. O não e o sim: a gênese da comunicação humana, São Paulo, Martins Fontes.

Spitz, René. [1887] 1979. O primeiro ano de vida: um estudo psicanalítico do desenvolvimento normal e anômalo das relações objetais, São Paulo, Martins Fontes.

Vasconcellos, Roseli. 1999. Paralisia Cerebral: a fala na escrita, Dissertação de Mestrado, LAEL/PUC, São Paulo.

Vasconcellos, Roseli. 2006. Fala, escuta, escrita: a relação sujeito-linguagem no caso de uma criança com paralisia cerebral que não oraliza, em Maria Francisca Lier-DeVitto \& L. Arantes (org.), Aquisição, Patologias e Clínica de Linguagem, São Paulo, EDUC/FAPESP: 289-311.

Vasconcellos, Roseli. 2010. Organismo e sujeito: uma diferença sensível nas paralisias cerebrais, Tese de Doutorado, LAEL/PUC, São Paulo. 